\title{
APLIKASI GAME EDUKASI MATEMATIKA TINGKAT DASAR BERBASIS ANDROID
}

\author{
Eko Gunawan ${ }^{1)}$, Sulistyowati ${ }^{2)}$, Lili Rusdiana ${ }^{3)}$ \\ 1,2,3 Teknik Informatika, STMIK Palangkaraya \\ 1,2,3 Jl. G.Obos No.114 Palangka Raya \\ Email: ${ }^{1}$ egoen3397@gmail.com, ${ }^{2}$ sty.kireina@yahoo.com, ${ }^{3}$ fasliiana7@gmail.com
}

\begin{abstract}
Game is one of the applications that are favored by children. Not a few parents who allow their children to use a smartphone with various reasons such as so that children do not interfere with work, so that children do not neglect, and various other reasons. However, sometimes smartphones are misused only for playing games by children, so the time that should be used for learning is instead used for playing games only. So that the game does not only waste the child's time in vain, then built a game application for children based on the genre of fighter and education in the game of hero against monsters accompanied by mathematics learning. The features provided in the application are 4 types of questions such as addition, subtraction, multiplication, and division as well as 6 levels of problem difficulty level. By this basic level math game it can be an alternative in learning while playing games through smartphones. This game is able to be a fun learning media in learning mathematics for game users.
\end{abstract}

Keyword: Android, Application, Game, Education, Mathematics

\begin{abstract}
Abstrak
Game merupakan salah satu aplikasi yang digemari anak-anak. Tidak sedikit orang tua yang membiarkan anaknya untuk menggunakan smartphone dengan berbagai alasan seperti agar anak tidak mengganggu pekerjaan, agar anak tidak kelayapan, dan berbagai alasan lainnya. Namun, kadang smartphone disalahgunakan hanya untuk bermain game oleh anak-anak, sehingga waktu yang seharusnya digunakan untuk belajar malah digunakan untuk bermain game saja. Agar game tidak hanya membuang waktu anak dengan sia-sia, maka dibangun aplikasi game untuk anak berdasarkan genre fighter and education dalam permainan hero melawan monster disertai dengan pembelajaran matematika. Fitur yang disediakan dalam aplikasi yakni 4 jenis soal seperti penjumlahan, pengurangan, perkalian, dan pembagian serta 6 level tingkat kesulitan soal. Dengan adanya game matematika tingkat dasar ini maka dapat menjadi alternatif dalam belajar sambil bermain game melalui smartphone. Game ini mampu manjadi media pembelajaran yang menyenangkan dalam pembelajaran matematika untuk pengguna game.
\end{abstract}

Kata Kunci: Android, Aplikasi, Game, Edukasi, Matematika

\section{Pendahuluan}

Saat ini merupakan era yang mana anak usia dini telah dikelilingi oleh perkembangan kecanggihan teknologi. Teknologi yang berkembang dapat digunakan sesuai dengan kadar penggunaan dan waktunya agar bermanfaat bagi pengguna seperti halnya game yang seringnya menyita banyak waktu penggunanya. Anak dapat kecanduan bermain game sehingga waktu yang seharusnya digunakan anak untuk belajar tetapi malah digunakan untuk bermain Game.

Bermain game dapat berdampak positif maupun negatif, jika dilakukan sebentar maka dapat berdampak positif. Namun, jika dengan durasi yang lama dan dilakukan setiap hari maka hasilnya akan berbeda, yakni dapat berdampak negatif. Bermain game yang dilakukan oleh anak, dapat mengembangkan kemampuan otak anak yang berkaitan dengan kognitif atau kecerdasan logika- matematika seperti kemampuan dalam menghitung, logika dalam berpikir dan pemecahan masalah [1].

Berdasarkan dampak dan efektifitas dari perkembangan teknologi, maka dapat dijadikan sebagai suatu alternatif pembelajaran matematika yang dapat mempermudah anak dalam memahami pelajaran matematika dari sejak dini, sehingga matematika tidak lagi menjadi suatu hal yang membosankan bahkan menakutkan bagi anak sekolah. Dari semua jenis media pembelajaran interaktif, media pembelajaran melalui game atau permainan termasuk salah satu solusi yang memiliki nilai lebih, karena pada dasarnya game berfungsi sebagai hiburan dan dengan dijadikan sebagai media pembelajaran maka dapat membuat anak-anak menjadi lebih senang dalam belajar. Melalui game, selain dapat bermain, juga dapat belajar disaat yang bersamaan, sehingga waktu lebih bermanfaat. Aplikasi edukasi pembelajaran metamorfosis kupu-kupu menggunakan 
smartphone juga dapat menarik minat anak dalam belajar apalagi aplikasi disajikan dalam bentuk augmented reality [2]. Aplikasi edukasi dalam bentuk game yakni RPG matematika yang menyelipkan pengoperasian bilangan pada soal cerita kehidupan sehari-hari ke bentuk tokoh yang dalam perjalanan membeli buah-buahan, game ini dapat mengedukasi penggunanya [3]. Media pembelajaran berupa game edukasi berbasis RPG juga digunakan pada materi struktur atom [4].

Selain itu, aplikasi game edukasi berbasis dekstop dengan tema Timer Island untuk soal matematika juga memberikan hiburan dalam belajar berhitung bagi penggunanya [5]. Game matematika juga menarik minat anak dengan menampilkan gambar bintang sebagai pertanda jawaban benar dan menampilkan gambar piala ketika game berakhir jika game dimenangkan oleh pemain [6]. Aplikasi game edukasi matematika berbasis android yang interaktif juga lebih menantang bagi anak sebagai pemain karena operasi hitung yang dapat disajikan dalam bentuk aktor berupa ikan sebagai salah satu media belajar matematika. Alur penggunaan yakni dengan perintah agar mengarahkan ikan pada jawaban yang dipilih [7]. Game edukasi matematika juga tidak kalah menarik dengan penyajian materi menghitung luas permukaan bangun ruang sisi datar [8].

Ranah game edukasi mulai berkembang seiring dengan perkembangan teknologi dengan berbagai suguhan tampilan game yang dianimasikan untuk anakanak. Game edukasi pengenalan nama hewan dan habitatnya dalam 3 bahasa sebagai media pembelajaran berbasis multimedia, sebagai salah satu media pembelajaran yang efektif untuk membantu anak-anak dalam belajar [9]. Game edukasi berkembang juga sebagai media pembelajaran pendidikan anak usia dini dengan hasil yang diperoleh yakni permainan acak kata, berhitung puzzle, dan pilih simbol [10]. Game edukasi bertemakan matematika untuk sekolah dasar sebagai alternatif media pembelajaran dengan persentase meningkat ke 32\% dari belajar menggunakan buku Yaitu 28\% [11]. Dalam pembuatan game edukasi, diperlukan beberapa hal seperti pemilihan format media, pemilihan materi, dan penyusunan soal tes dalam game [12].

Matematika merupakan ratu (queen) sekaligus pelayan (servant) yakni dengan maksud bahwa matematika sebagai pelayan ilmu, matematika dapat dikreasikan untuk memberikan manfaat bagi ilmu pengetahuan yang lainnya. Matematika harus memberikan manfaat hagi semua orang yang mempelajarinya [13]. Matematika dasar diperlukan media manipulatif untuk membantu anak-anak dalam mempelajari matematika [14].

Android merupakan salah satu sistem operasi yang dapat dipergunakan pada telepon celullar dan komputer tablet layar sentuh (touch screen) dengan berbasis Linux [15]. Basis sistem operasi android adalah kernel linux yang merupakan open source sehingga sistem operasi android memungkinkan pengembang untuk selalu menciptakan aplikasi android sendiri yang bisa digunakan untuk berbagai macam alat yang bergerak (mobile).
Aplikasi untuk pembelajaran aksara sunda dapat diimplementasikan pada android [16].

\section{Metode}

Data yang digunakan yakni dalam aplikasi game ini yakni adanya nama pemain, waktu, skor, pengurangan kesempatan bermain, hero sebagai objek dari game ini untuk menggambarkan karakter pemain, monster merupakan objek yang harus dikalahkan oleh pemain, soal, dan jawaban. Data tersebut digunakan dalam aplikasi game edukasi matematika yang dibangun. Ruang lingkup atau objek dari penelitian ini yaitu Anak sebagai pengguna aplikasi, khususnya untuk anak sekolah dasar dan smartphone sebagai alat yang digunakan.

Bahan dan alat utama yang digunakan dalam penelitian ini yakni :

a. Rancangan alur penggunaan aplikasi dengan menggunakan use case diagram

Unified Modeling Language (UML) merupakan penggambaran bahasa dengan menggunakan simbol gambar yang dipakai untuk menggambarkan hubungan satu dengan yang lainnya [17]. Seperti use case diagram yang menggambarkan fungsional dari sebuah sistem dengan merepresentasikan sebuah interaksi antara aktor dengan sistem. UML digunakan dalam perancangan untuk game edukasi matematika dengan tema mathreasure hunter [18].

Gambar 1 menunjukkan use case diagram yang menggambarkan interaksi antara aktor dengan sistem dan fungsionalitas dari aplikasi game. Tampak pemain sebagai aktor, pemain dapat memilih jenis soal, memilih level kesulitan dalam memainkan game, melihat soal, menjawab soal, dan melihat animasi dari game yang dimainkan.

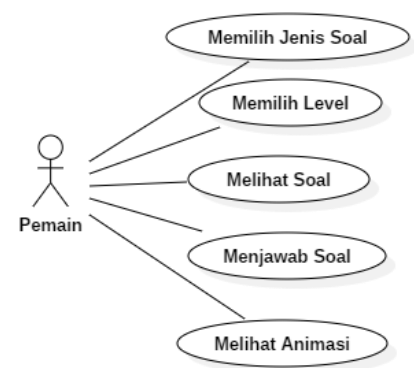

Gambar 1. Use case diagram game edukasi matematika

b. Perangkat lunak yang mendukung dalam pengolahan aplikasi yaitu sistem operasi Windows 10, Game Maker Studio, Android versi 9, Adobe Photoshop.

c. Komponen game

Komponen pendukung yang ditampilkan dalam game ditampilkan seperti pada tabel 1. Karakter tokoh untuk hero dan monster menggunakan karakter dari situs website penyedia karekater [19]. 
Tabel 1. Desain tampilan komponen pendukung game

\begin{tabular}{|c|c|c|}
\hline No & Tampilan & Keterangan \\
\hline 1 & & $\begin{array}{l}\text { Nama yang telah } \\
\text { diisikan di menu login. }\end{array}$ \\
\hline 2 & & $\begin{array}{lr}\text { Merupakan } & \text { waktu } \\
\text { hitung mundur batas } \\
\text { mengerjakan sebuah } \\
\text { soal. }\end{array}$ \\
\hline 3 & Skkor & Skor yang diperoleh. \\
\hline 4 & Darah & $\begin{array}{l}\text { Bar darah yang akan } \\
\text { berkurang } r \text { untuk } \\
\text { menentukn menang } \\
\text { kalahnya pemain. }\end{array}$ \\
\hline 5 & & $\begin{array}{l}\text { Hero adalah sebuah } \\
\text { objek yang akan } \\
\text { digunakan oleh pemain } \\
\text { melawan monster. }\end{array}$ \\
\hline 6 & & $\begin{array}{l}\text { Monster adalah sebuah } \\
\text { objek yang harus } \\
\text { dikalahkan pemain. }\end{array}$ \\
\hline 7 & Soal & $\begin{array}{l}\text { Soal yang harus } \\
\text { dijawab. }\end{array}$ \\
\hline 8 & Jawab & $\begin{array}{l}\text { Menu jawab digunakan } \\
\text { untuk menjawab soal. }\end{array}$ \\
\hline 9 & Tombel Input & $\begin{array}{l}\text { Tombol input berisi } \\
\text { angka 1-10 dan } 2 \\
\text { tombol tambahan } \\
\text { (hapus dan Ok). Tombol } \\
\text { hapus digunakan untuk } \\
\text { menghapus angka input } \\
\text { jika salah dalam } \\
\text { pengetikan dan tombol } \\
\text { ok digunakan untuk } \\
\text { mengeksekusi jawaban } \\
\text { yang telah dijawab yang } \\
\text { nanti akan } \\
\text { diekspresikan melalui } \\
\text { animasi hero dan } \\
\text { monster. }\end{array}$ \\
\hline
\end{tabular}

Adapun tata cara permainan dalam game ini sebagai berikut:

a. Pemain akan menang jika darah monster telah habis dan telah mengalahkan 4 monster.

b. Pemain akan kalah jika darah hero telah habis. c. Dalam satu level terdapat 4 monster yang harus di kalahkan secara bergantian.

d. Darah hero akan berkurang jika jawaban salah atau waktu menjawab habis.

e. Darah monster akan berkurang jika jawaban hero benar.

Teknik pengumpulan data dilakukan dengan cara sebagai berikut :

a. Observasi

Obrservasi yang dilakukan yakni mengobservasi kegiatan yang dilakukan anak-anak saat menggunakan smartphone. Baik dari kegemaran mereka terhadap game maupun dalam belajar matematika.

b. Studi Literatur

Teknik ini dilakukan yakni dengan cara mencari sumber literatur yang pernah di buat sebelumnya oleh peneliti atau penulis lainnya seperti jurnal, buku dan dari website mengenai game edukasi.

\section{Hasil dan Analisa}

a. Hasil

Penelitian yang dilakukan menghasilkan aplikasi game eddukasi matematika tingkat dasar yang diimplementasikan dalam sistem operasi android. Tampilan menu untuk mengisikan nama pemain seperti pada gambar 2. Terdapat tombol input nama yang harus diisi oleh pengguna sebelum memulai game.

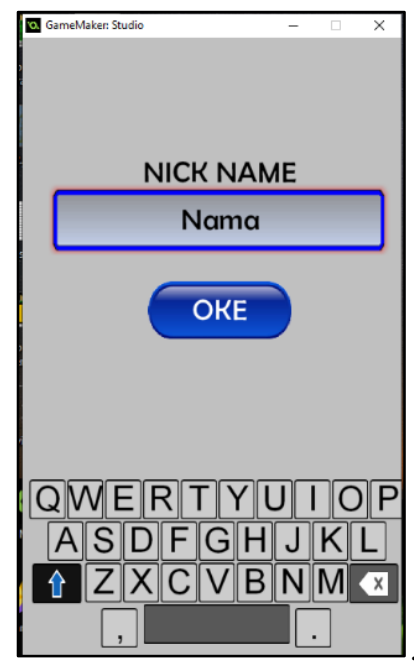

Gambar 2. Tampilan pengisian nama pemain

Tampilan menu utama seperti pada gambar 3 terdapat 2 pilihan menu yakni tombol mulai dan tombol info. Tombol mulai untuk melakukan atau memulai game dan tombol info untuk menampilkan informasi mengenai game, termasuk tata cara penggunaan game tersebut. 


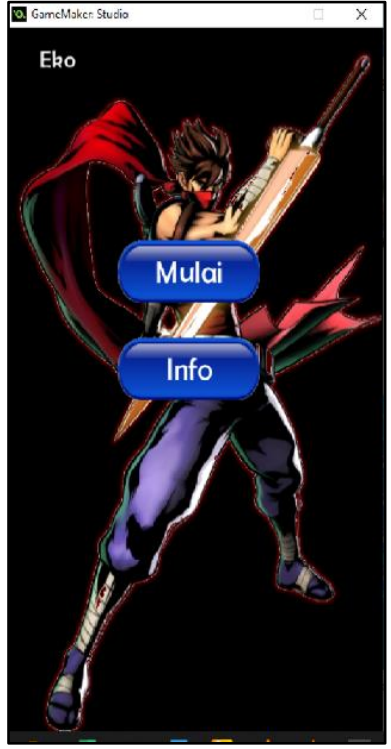

Gambar 3. Tampilan menu utama game edukasi matematika

Gambar 4 menampilkan pemilihan jenis soal yakni terdapat 4 jenis soal yang dapat di pilih seperti penambahan, pengurangan, perkalian, dan pembagian.

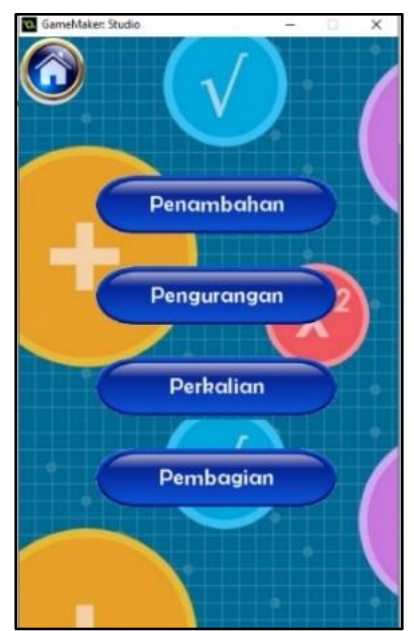

Gambar 4. Tampilan pilihan soal

Gambar 5 menampilkaan pemilihan level tingkat kesulitan dalam bermain. Terdapat 6 tombol yang berdasarkan nomor urut angka yakni 1, 2, 3, 4, 5, dan 6, dengan kesulitan masing-masing yang berbeda dari tingkat 1 dan meningkat lagi kesulitannya sampai ke level 6.

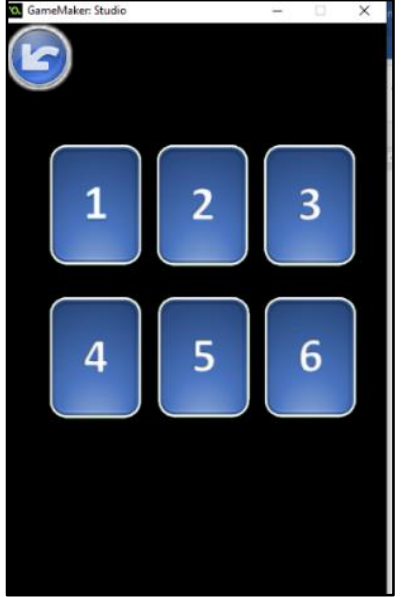

Gambar 5. Tampilan pilih level kesulitan

Gambar 6 menampilkan permaian yang dilakukan. Tampak hero dan monster yang akan bermain dan menampilkan nomor perhitungan.

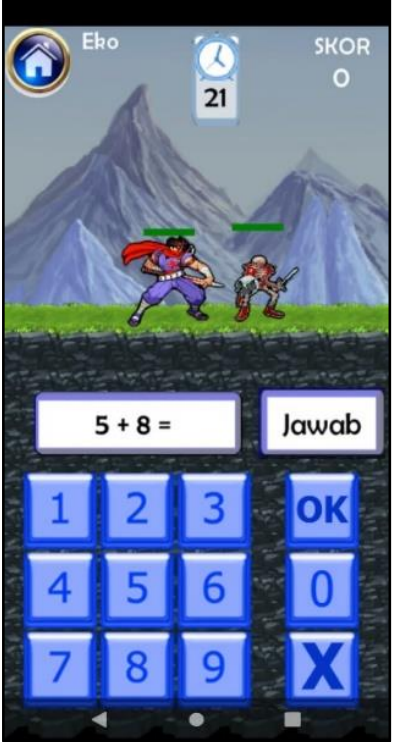

Gambar 6. Tampilan permainan dalam game

Pengujian yang dilakukan pada aplikasi ini dengan menggunakan pengujian alpha. Pada pengujian alpha berfokus pada persyaratan fungsional perangkat lunak untuk memastikan bahwa aplikasi dapat berjalan dengan benar sesuai kebutuhan dan tujuan yang diharapkan terhadap aplikasi yang telah dibangun seperti yang terdapat pada tabel 2 .

Tabel 2. Pengujian alpha pada game

\begin{tabular}{|c|c|c|c|}
\hline No & Interface & Output & Hasil \\
\hline 1 & 2 & 3 & 4 \\
\hline 1 & Splash & Splash screen bekerja & Ok \\
\hline & screen & & \\
\hline 2 & Login & Tampilan login bekerja & Ok \\
\hline 3 & Main menu & $\begin{array}{l}\text { Tampilan menu utama } \\
\text { bekerja }\end{array}$ & Ok \\
\hline 4 & Info & Tampilan info bekerja & Ok \\
\hline 5 & $\begin{array}{l}\text { Pilih jenis } \\
\text { soal }\end{array}$ & $\begin{array}{l}\text { Tampilan pilih jenis } \\
\text { soal bekerja }\end{array}$ & Ok \\
\hline
\end{tabular}




\begin{tabular}{|c|c|c|c|}
\hline 6 & Pilih level & $\begin{array}{l}\text { Tampilan pilih level } \\
\text { kesulitan permainan } \\
\text { bekerja }\end{array}$ & Ok \\
\hline 7 & Pertambahan & $\begin{array}{l}\text { Tampilan menu game } \\
\text { pertambahan bekerja }\end{array}$ & Ok \\
\hline 8 & Pengurangan & $\begin{array}{l}\text { Tampilan menu game } \\
\text { pengurangan bekerja }\end{array}$ & Ok \\
\hline 9 & Perkalian & $\begin{array}{l}\text { Tampilan menu game } \\
\text { perkalian bekerja }\end{array}$ & Ok \\
\hline 10 & Pembagian & $\begin{array}{l}\text { Tampilan menu game } \\
\text { pembagian bekerja }\end{array}$ & Ok \\
\hline 11 & $\begin{array}{l}\text { Animasi } \\
\text { Hero }\end{array}$ & $\begin{array}{l}\text { Tampilan animasi hero } \\
\text { bekerja }\end{array}$ & Ok \\
\hline 12 & $\begin{array}{l}\text { Animasi } \\
\text { Monster }\end{array}$ & $\begin{array}{l}\text { Tampilan animasi } \\
\text { monster bekerja }\end{array}$ & Ok \\
\hline
\end{tabular}

Dari hasil pengujian yang dilakukan pada tabel 2, dapat ditarik kesimpulan bahwa sistem sudah dapat berjalan sesuai dengan yang diharapkan. Maka, secara fungsinoal sistem sudah dapat menghasilkan keluaran yang diharapkan.

\section{b. Analisa}

Berdasarkan gambar 2 yang menunjukkan penggunaan aplikasi dimulai dengan mengisi nama pemain atau pengguna yang nantinya akan dianggap sebagai hero dalam game. Kemudian memilih jenis perhitungan matematika yang akan dimainkan, selanjutnya memilih level tingkat kesulitan yang dapat dimainkan oleh pengguna. Level ini nantinya akan berimbas pada permainan hero yang dimainkan dan tingkat kesulitan dalam menjawab pertanyaan.

Gambar 6 menunjukkan tampilan permainan yang dimainkan oleh pengguna, disuguhkan tampilan hero dan monster yang nantinya merupakan hasil dari jawaban yang diberikan oleh pengguna terhadap soal yang diberikan. Pemain akan mendapat soal pertanyaan dari setiap level berdasarkan pemilihan soal yakni penjumlahan, pengurangan, perkalian, atau pembagian. Setelah selesai menjawab soal dari setiap level tersebut, selanjutnya jika jawaban benar maka darah monster berkurang dan dilanjutkan dengan soal berikutnya hingga darah monster habis maka pemain diteruskan ke bagian hasil akhir yang menampilkan total skor. Sebaliknya, jika jawaban salah, maka darah hero berkurang dan dikembalikan ke bagian melihat soal dan animasi hingga jawaban benar atau darah hero habis maka pemain di nyatakan kalah.

Game android ini dapat memudahkan anak untuk belajar dan menarik minat akan karena diselingi permainan yang edukatif, mendidik anak-anak belajar di bidang pelajaran matematika dasar, sehingga permainan yang dilakukan dapat mengasah otak, melatih kecepatan dan ketepatan dalam menjawab pertanyaan.

\section{Kesimpulan}

Game matematika tingkat dasar dibuat menggunakan program game maker studio 1.4 dan dapat dijalankan dengan baik pada perangkat mobile yang berplatform android dengan sistem operasi android kitkat dan versi di atasnya. Serunya, agar anak dapat mempertahankan hero nya maka anak harus menjawab pertanyaan dengan benar hingga mendapat hasil akhir berupa kemenangan sampai dapat mengalahkan monster. Permainan dalam game ini selain menarik untuk anak dalam belajar, melatih daya pikir, juga dapat menambah daya ingat pemain saat menikmati permainan.

\section{Daftar Pustaka}

[1] K. P. Putra, T. P. E. Sanubari, \& T. F. Manggena, "Pengaruh Intensitas Bermain Game Terhadap Tingkat Kognitif (Kecerdasan Logika-Matematika) Usia 8-9 Tahun," vol. 33, no. 2, hal. 146-153. 2017.

[2] F. Ningsih, L. Rusdiana, \& Rudini, "Analisis Dan Desain Aplikasi Pembelajaran Metamorfosis KupuKupu Berbasis Augmented Reality," vol. 2, no. 2, hal. 118-123. 2019.

[3] S. A. Pramuditya, M. S. Noto, \& D. Syaefullah, "Game Edukasi RPG Matematika," vol. 6, no. 1, hal. 77-84. 2017.

[4] K. W. Sari, S. Saputro, \& B. Hastuti, "Pengembangan Game Edukasi Kimia Berbasis Role Playing Game ( RPG ) Pada Materi Struktur Atom Sebagai Media Pembelajaran Mandiri Untuk Siswa," vol. 3, no. 2, hal. 96-104. 2014.

[5] M. Yunus, I. F. Astuti, \& D. M. Khairina, "Game Edukasi Matematika Untuk Sekolah Dasar,” vol. 10, no. 2, hal. 59-64. 2015.

[6] Q. J. Adrian \& Apriyanti, "Game Edukasi Pembelajaran Matematika Untuk Anak Sd Kelas 1 dan 2 Berbasis Android," vol. 13, no. 1, hal. 51-54. 2019.

[7] A. Ikwan, M. S. Mauluddin, \& Mustagfirin, “Aplikasi Game Edukasi Matematika Fish Math Berbasis Android," no. Prosiding SNST ke-8 Fakultas Teknik Universitas Wahid Hasyim Semarang 65, hal. 65-69. 2017.

[8] A. Rizal \& K. Hernawati, "Pengembangan Game Edukasi Matematika Dengan Pendekatan Guided Discovery Untuk Siswa SMP Kelas VIII," vol. 6, no. 3, hal. 1-8. 2017.

[9] R. A. Rahman \& D. Tresnawati, "Pengembangan Game Edukasi Pengenalan Nama Hewan dan Habitatnya Dalam 3 Bahasa Sebagai Media Pembelajaran Berbasis Multimedia," vol. 13, no. 1, hal. 184-190. 2016.

[10] A. V. Vitianingsih, "Game Edukasi Sebagai Media Pembelajaran Pendidikan Anak Usia Dini," vol. 1, no. 1, hal. 1-8. 2016.

[11] J. A. Yustin, H. Sujaini, \& M. A. Irwansyah, "Rancang Bangun Aplikasi Game Edukasi Pembelajaran Matematika Menggunakan Construct 2," vol. 1, no. 1, hal. 1-5. 2016.

[12] S. A. Pramuditya, M. S. Noto, \& H. Purwono, "Desain Game Edukasi Berbasis Android pada Materi Logika Matematika," vol. 2, no. 2, hal. 165179. 2018.

[13] A. Prabowo, Matematika: Menguak Indahnya Bilangan. Klaten: Intan Pariwara, 2018. 
[14] A. Amir, "Pembelajaran Matematika SD Dengan Menggunakan Media Manipulatif," vol. VI, no. 01, hal. 72-89, 2014.

[15] A. D. Kasman, Trik Kolaborasi Android dengan PHP \& MySQL. 2015.

[16] H. Fatah, N. Ichsan, T. Wahyuni, E. Ernawati, \& Indriyanti, "Rancang Bangun Program Aplikasi Pembelajaran Aksara Sunda Berbasis Android," vol. 9, no. 2, hal. 304-320. 2020.

[17] P. Kimmel, UML Demystified. Los Angeles: McGraw-Hill Education, 2015.
[18] M. Adiwijaya, K. I. Satoto, \& Y. Christyono, "Perancangan Game Edukasi Platform Belajar Matematika Berbasis Android Menggunakan Construct 2," vol. 4, no. 1, hal. 128-133. 2015.

[19] Http://www.spreatdatabase.com. Diakses 1 Oktober 2019 